Article type : Case Report

6

7

8

9

6

7

8

\title{
Unique cytologic and histologic features of a suspected cutaneous xanthoma in a dog
}

Elise B Russell

\section{Natalie F Courtman}

U-Vet Werribee Animal Hospital and Faculty of Veterinary and Agricultural Sciences, The University of Melbourne, Werribee, VIC, Australia

\section{Correspondence}

E. Russell, Faculty of Veterinary and Agricultural Sciences, The University of Melbourne, 250 Princes Hwy, Werribee, Victoria 3030, Australia

Email: elise.russell@unimelb.edu.au

\section{ABSTRACT}

A 4-year-old spayed female American Staffordshire terrier presented to the U-Vet Animal Hospital, Werribee, Australia, with a cutaneous mass that had been slowly growing over 12 months. Cytologic evaluation showed cohesive to individualized, vacuolated spindled cells often arranged in a perivascular pattern. The mass was completely excised, and the histopathologic examination demonstrated sheets of vacuolated spindled to round cells expanding the full thickness of the dermis. The cells demonstrated both Iba1 and CD18 antibody binding, leading to an initial interpretation of histiocytic sarcoma. Given the discordance with the clinical presentation, further immunohistochemistry (IHC) was performed. The cells demonstrated strong CD204 antibody binding and did not bind the E-cadherin antibody, consistent with dermal macrophage origin. Ki-67 antibody binding was regionally variable from $<5-25 \%$, with more regions that had low Ki-67 expression.

This is the author manuscript accepted for publication and has undergone full peer review but has not been through the copyediting, typesetting, pagination and proofreading process, which may lead to differences between this version and the Version of Record. Please cite this article as doi: $10.1111 /$ VCP.12804

This article is protected by copyright. All rights reserved 
Fasted serum biochemistry revealed hypertriglyceridemia and persistent hypercholesterolemia. Based on clinical, microscopic, biochemical, and IHC results, the final interpretation was an indolent dermal histiocytic proliferation of macrophage origin, with a preference for cutaneous xanthoma or reactive dermal fibrohistiocytoma.

\section{KEYWORDS}

Benign fibrohistiocytoma, foam cells, histiocytic, hyperlipidemia, immunohistochemistry, xanthogranuloma

\section{CASE PRESENTATION}

A 4-year-old female spayed $35.6 \mathrm{~kg}$ American Staffordshire Terrier was presented to the U-Vet Animal Hospital, Werribee, Victoria, Australia, for routine vaccination and evaluation of a mass on the ventral thorax which had been slowly growing over the preceding 12 months. The dog had otherwise been clinically well but was overweight (BCS 8/9). Physical examination demonstrated an $8 \mathrm{~mm}$ firm raised alopecic cutaneous mass in the right pectoral region. Fine-needle aspiration (FNA) of the mass was performed.

Cytopathology revealed highly to poorly cellular smears comprising apparently cohesive to individualized round to spindled cells often present in a striking perivascular arrangement, amongst a pale blue proteinaceous background with abundant fine, clear vacuoles (Figure $1 \mathrm{~A})$. The cells had round to oval nuclei with coarsely stippled chromatin and 1-3 variably distinct nucleoli. The cytoplasm was abundant, often highly vacuolated, and pale blue with indistinct cell borders. The cells displayed mild anisocytosis and mild to moderate anisokaryosis with occasional irregular nuclear borders. Occasional large irregular nucleoli were noted. Rare inflammatory cells comprising small lymphocytes, plasma cells, and eosinophils were also noted (Figure 1B).

The cytologic interpretation was soft-tissue sarcoma, likely liposarcoma, based on the high cellularity, striking perivascular pattern, spindle cell morphology, and marked vacuolation. Differentials included perivascular wall tumor (PWT) or sebaceous carcinoma. An excisional biopsy with wide margins was recommended.

Excision was performed 10 days later, and histopathology demonstrated a highly cellular, unencapsulated, mildly infiltrative proliferation of sheets of spindled to round cells, which infiltrated and expanded the full thickness of the dermis (Figures 2A and 2B). The cells had moderate amounts of vacuolated pink cytoplasm and indistinct cell borders. Vacuoles were small and numerous, clear, and had distinct borders. The nuclei were plump to ovoid with lacy chromatin with a single nucleolus (Figure $2 \mathrm{C}$ ). Mitoses were two per ten $400 x$ fields. There was mild to moderate anisokaryosis. 
Multifocally, and throughout the mass, were small numbers of plasma cells and lymphocytes.

Excision was complete with $6 \mathrm{~mm}$ lateral margins and $12 \mathrm{~mm}$ deep margins.

Immunohistochemistry with CD18 (mouse monoclonal, CA16.3.C10; Peter Moore, Davis, CA, USA) and ionized calcium-binding adapter molecule 1 (Iba1, rabbit polyclonal; Metagene, Brisbane, QLD, Australia) antibodies, using canine lymph nodes as positive controls, demonstrated moderate diffuse membranous binding of the CD18 antibody and strong diffuse membranous binding of the Iba1 antibody, reflecting a histiocytic origin (Figure 3). Given the histologic and IHC results, an initial diagnosis of histiocytic sarcoma was made, and screening for metastasis was recommended.

Thoracic radiographs and abdominal ultrasound were performed; both were unremarkable. Focused ultrasonographic examination of the right axillary lymph node, however, demonstrated moderate enlargement (width: $1.28 \mathrm{~cm}$ ), with normal echogenicity and margins. FNA was performed, and smears demonstrated an unremarkable lymph node cytologically; however, slides were noted to be of low cellularity, and thus the cause of the lymphadenopathy was not determined. Fasting serum biochemistry results, at this time, revealed a moderate hypercholesterolemia $(348.0 \mathrm{mg} / \mathrm{dL}$; reference interval (RI) $150.8-301.6 \mathrm{mg} / \mathrm{dL}$ ). The CBC demonstrated mild hyperhemoglobinemia $(19.2 \mathrm{~g} / \mathrm{dL} ; \mathrm{RI} 12.0-18.0 \mathrm{~g} / \mathrm{dL})$ and moderate reticulocytosis $\left(209 \times 10^{3} / \mu \mathrm{L} ; \mathrm{RI} 10-110 \times 10^{3} / \mu \mathrm{L}\right)$ in the absence of anemia (HCT 52\%; RI 37-55\%) with moderately hemolyzed plasma.

Formalin-fixed samples were submitted to the University of California, Davis, CA, USA for further immunohistochemistry. The round to spindled cells demonstrated strong CD204 antibody binding, and no E-cadherin antibody binding, suggesting a dermal macrophage origin for the mass. Ki-67 antibody binding was highly and regionally variable, from below $5 \%$ to $25 \%$, though the wellexpressed regions were less frequent than the poorly-expressed regions.

A year later, fasted serum cholesterol and triglyceride testing demonstrated moderate hypertriglyceridemia $(407.4 \mathrm{mg} / \mathrm{dL} ; \mathrm{RI} 8.9-141.7 \mathrm{mg} / \mathrm{dL})$, and persistent moderate hypercholesterolemia (351.9mg/dL; RI 150.8-301.6mg/dL). The serum total thyroxine concentration was within normal limits $(2.03 \mu \mathrm{g} / \mathrm{dL} ; \mathrm{RI} 1.01-3.96 \mu \mathrm{g} / \mathrm{dL})$. There was no evidence of recurrence at the surgical site, and no additional masses were noted. The dog remained clinically well, with only a single episode of self-limiting gastrointestinal upset eight months after biopsy. Given the clinical and immunohistochemical findings, the mass was diagnosed as an indolent dermal histiocytic proliferation of macrophage origin, with a preference for cutaneous xanthoma or, less likely, reactive dermal fibrohistiocytoma. The dog subsequently re-presented 18 months after initial biopsy for the presence of a $1 \mathrm{~cm}$ diameter firm raised erythematous haired mass on the medial aspect of 
the first digit of the left forepaw and right-sided otitis externa. Cytology of the digital mass was nondiagnostic due to poor cellularity, and the mass resolved spontaneously.

\section{DISCUSSION}

Cutaneous xanthomas have been described in a variety of veterinary species, most frequently in avian species ${ }^{1,2}$, but also rarely in cats ${ }^{3-6}$, and very rarely in $\operatorname{dog} s^{7,8}$, horses ${ }^{9}$, rabbits ${ }^{10}$. They are nonneoplastic masses composed of large foamy lipid-laden macrophages and are usually associated with defects in lipid metabolism or with metabolic disorders such as diabetes mellitus, hypothyroidism, or hyperadrenocorticism ${ }^{11,12}$. Rarely, solitary xanthomas have been reported in the absence of abnormalities in lipid metabolism ${ }^{7,10}$.

The dog, in this case, had persistent fasting moderate hypercholesterolemia and hypertriglyceridemia. Hyperlipemia in dogs may be primary or secondary to underlying nephrotic syndrome, hypothyroidism, cholestatic disease, or pancreatitis ${ }^{13}$. Hypothyroidism was considered unlikely based on normal serum thyroxine concentrations, and other secondary causes were considered unlikely given the lack of supportive biochemical or clinical findings; however, obesity might have been a predisposing factor ${ }^{13-15}$. As such, a low-fat diet and weight loss were recommended.

Initial moderate reticulocytosis in the absence of anemia was attributed to hemorrhage associated with surgical biopsy two weeks prior, post-operative carprofen administration, and/or excitement/splenic contraction; however, hemolysis could not be excluded. Given the normal red cell count $\left(8.4 \times 10^{9} / \mathrm{dL} ; \mathrm{RI} 5.5-8.5 \times 10^{\%} / \mathrm{dL}\right)$, the hyperhemoglobinemia was likely an artifact of moderate sample hemolysis or could have reflected concurrent hyperlipidemia masked by hemolysis.

Hemogram monitoring was not performed; however, the dog remained clinically well, and there was no clinical evidence of hemorrhagic or hemolytic disease on subsequent follow-up examinations.

Commonly affected sites for cutaneous xanthomas are species-dependent, and in dogs, cutaneous xanthomas have been reported on the face, ears, and ventrum. In humans, the tuberous and eruptive forms characteristically form at sites of pressure and minor trauma ${ }^{16}$. This is postulated to be due to histamine release causing increased vascular permeability facilitating accelerated xanthoma formation ${ }^{17}$. While there was no history of trauma to the affected site, in this case, it is interesting to note that the single report of a solitary cutaneous xanthoma in a dog was also present on the ventral thorax. In that case, cutaneous mast cell tumors were also present ${ }^{7}$, and it could be 
speculated that histamine-mediated mechanisms could have increased susceptibility to xanthoma formation. There was no evidence of mast cell neoplasia in this case.

While the cytologic and histologic preparations demonstrated the characteristic and prominent vacuolation observed in cutaneous xanthomas, there were several unique microscopic features in this case. Firstly, the striking perivascular arrangement of cells noted on cytology, a common feature of perivascular wall tumors, liposarcomas, and Leydig cell tumors on cytology ${ }^{18-20}$, has not previously been reported in xanthomas and led to the initial incorrect cytologic interpretation. This pattern has been reported in diffuse normolipemic plane xanthoma in humans, a type of xanthoma that occurs secondary to perivascular immunoglobulin deposition associated with plasma cell neoplasia, monoclonal paraproteinemia, leukemia, and lymphoma ${ }^{21}$, but to the authors' knowledge, has not been reported in other forms of xanthoma. Previous studies in humans have demonstrated that endothelial cells appear to play a role in xanthoma development, by increasing von Willebrand factor and E-selectin expression and undergoing proliferation to promote macrophage migration into xanthomatous lesions ${ }^{22}$. If this also occurs in animals, it could explain the perivascular arrangement observed in this case. Additionally, the frequent spindled morphology of histiocytes, both cytologically and on histopathology, initially resulted in an erroneous interpretation of a sarcoma. The additional finding of diffuse immunohistochemical binding of CD18 and Iba1 antibodies further confused the preliminary interpretation by suggesting a histiocytic sarcoma was present, a more common malignant cutaneous neoplasm of $\operatorname{dogs}^{23}$. While the high cellularity, spindled morphology, and perivascular pattern on cytology could have supported a PWT; however, these tumors do not typically bind the CD18 antibody ${ }^{24}$.

The spindled morphology of histiocytes has been reported in solitary reticulohistiocytoma and cellular spindled histiocytic pseudotumor complicating fat necrosis in humans, and reactive fibrohistiocytic nodules in humans and dogs ${ }^{17,25}$. To the authors' knowledge, spindled histocytes have not been reported in cutaneous xanthomas, which are typically characterized by the presence of large round macrophages filled with lipid, sometimes termed "foam cells".

Reactive fibrohistiocytic nodules are uncommon in dogs and, as such, are poorly characterized. They are described as solitary or occasionally multiple small cutaneous nodules that predominantly affect dogs less than three years of age. Histologically these nodules comprise predominantly histiocytic cells with round to polygonal to plump spindle morphology that contain variable numbers of vacuoles. Fibroblasts and mixed lymphocytic, neutrophilic, and eosinophilic infiltrates might also be present. These lesions are postulated to be reactive, with excision being curative. ${ }^{25}$ While the spindled morphology of the histiocytes, in this case, was most consistent with a reactive 
fibrohistiocytic nodule, the clinical observation of hyperlipidemia and marked vacuolation of the histiocytes in the absence of significant inflammation was more consistent with cutaneous xanthoma, and as such was the favored interpretation.

Unfortunately, neither unstained smears nor frozen tissue samples were available in this case for Oil Red O or Sudan Black B staining for confirmation of lipid within macrophages. IHC, however, was essential for the identification of these cells.

$\mathrm{CD} 18$ is a $\beta_{2}$ integrin that is a major adhesion molecule for most leukocytes, however macrophages and granulocytes express ten-fold more CD18 than do lymphocytes ${ }^{12}$. Iba1 is a protein involved in rearrangement of the actin cytoskeleton that is present in cells of the monocyte/macrophage lineage in mice, and has been demonstrated in canine histiocytic sarcomas; however, it has also been shown to label dendritic cells ${ }^{26}$. CD204 is of the scavenger receptor superfamily and similarly labels cells of the monocyte/macrophage lineage; however, this molecule does not label dendritic cells. It has also been demonstrated in canine histiocytic sarcomas ${ }^{27}$. E-cadherin is a member of the calcium-dependent cadherin family of adhesion molecules and is expressed in canine Langerhans cells and canine cutaneous histiocytoma ${ }^{28}$. Thus, the IHC profile, in this case, supported monocyte/macrophage origin, rather than Langerhans cells (which comprise canine cutaneous histiocytoma ${ }^{28}$. Ki67 is a nuclear protein expressed in all phases of the cell cycle and is absent in non-cycling cells ${ }^{12}$; its low expression and regional variability, in this case, was supportive of a benign, reactive process rather than a proliferative malignant neoplasm (ie, histiocytic sarcoma), consistent with the clinical presentation.

In conclusion, this case report describes the unique cytologic and histologic features, including a perivascular arrangement and round to spindled morphology, of a suspected cutaneous xanthoma in a dog. The spindled to round morphology combined with positive CD18 and Iba1 immunohistochemical antibody binding, initially led to an erroneous interpretation of histiocytic sarcoma, which has markedly different clinical management and prognosis to both cutaneous xanthomas and reactive fibrohistiocytomas, which are reactive, rather than neoplastic, lesions. Further, IHC and biochemistry were helpful for accurate interpretation in this case.

\section{ACKNOWLEDGMENTS}

The authors thank Dr. Peter Moore of UC Davis for his assistance with CD204, E-cadherin, and Ki67 $\mathrm{IHC}$, and the interpretation of this case, and the pathology department at the University of Melbourne, Australia 


\section{REFERENCES}

1. Jaensch SM, Butler R, O'Hara A, Raidal SR, Wyatt K. Atypical multiple, papilliform, xanthomatous, cutaneous neoplasia in a goose (Anser anser). Aust Vet J. 2002;80:277-280.

2. Schmidt RE, Reavill DR, Phalen DN. Pathology of pet and aviary birds. 2nd ed. Ames, IA: John Wiley and Sons, Inc.; 2015.

3. Chanut F, Colle MA, Deschamps JY, Albaric O, Wyers M. Systemic xanthomatosis associated with hyperchylomicronaemia in a cat. J Vet Med A. 2005;52:272-274.

4. Vitale CB, Ihrke PJ, Gross TL. Diet-induced alterations in lipid metabolism and associated cutaneous xanthoma formation in 5 cats. Proceedings from the Third World Congress of Veterinary Dermatology. Edinburgh, Scotland, September 11-14, 1996:243-249.

5. Vogelnest $\measuredangle J$. Cutaneous xanthomas with concurrent demodicosis and dermatophytosis in a cat. Aust Vet J. 2001;79:470-475.

6. Wisselink MA, Koeman JP, Wensing T, de Bruijne J, Willemse T. Hyperlipoproteinaemia associated with atherosclerosis and cutaneous xanthomatosis in a cat. Vet Q. 1994:199-202. xanthoma in a dog. Vet Clin Path. 2011;40:95-98. 
8. Chastain CB, Graham CL. Xanthomatosis secondary to diabetes mellitus in a dog. J Am Vet Med Assoc. 1978;172:1209-1211.

9. Cohen RD, Scott DW, Erb HN. Prevalence, number and morphological types of multinucleated histiocytic giant cells in equine inflammatory dermatoses: A retrospective light microscopic study of skin-biopsy specimens from 362 horses. Equine Vet J. 2009;41:406-409.

10. Mentré V, Bulliot C. Idiopathic cutaneous xanthoma in a pet rabbit. Lab anim. 2014;43:271274.

11. Hargis A, Myers S. The Integument. In: Pathologic Basis of Veterinary Disease. 5th ed. St. Louis, MO: Elsevier; 2017:1109-1146.

12. Meuten DJ. Tumors in Domestic Animals. 5th ed ed. Ames, IA: John Wiley \& Sons Inc; 2017.

13. Xenoulis PG, Steiner JM. Canine hyperlipidaemia. J Small Anim Pract. 2015;56:595-605.

14. Jeusette IC, Lhoest ET, Istasse LP, Diez MO. Influence of obesity on plasma lipid and lipoprotein concentrations in dogs. Am J Vet Res. 2005;66(1):81-86.

15. Chikamune T, Katamoto H, Ohashi F, Shimada Y. Serum lipid and lipoprotein concentrations in obese dogs. J Vet Med Sci. 1995;57(4):595-598.

16. Walton KW, Thomas C, Dunkerley DJ. The pathogenesis of xanthomata. J Pathol. 1973;109(4):271-289.

17. Goldblum JR, Folpe AL, Weiss SW, Enzinger FM, Weiss SW. Enzinger and Weiss's Soft Tissue Tumors. 6th ed. Philadelphia, PA: Saunders/Elsevier; 2014.

18. Masserdotti C. Architectural patterns in cytology: correlation with histology. Vet Clin Pathol. 2006;35(4):388-396.

19. Piseddu E, De Lorenzi D, Freeman K, Masserdotti C. Cytologic, histologic, and immunohistochemical features of lingual liposarcoma in a dog. Vet Clin Pathol. 2011;40(3):393-397.

20. Masserdotti C, Bonfanti U, Lorenzi D, Ottolini N. Use of Oil Red O stain in the cytologic diagnosis of canine liposarcoma. Vet Clin Pathol. 2006;35(1):37-41.

21. Busam KJ. Dermatopathology. 2nd ed. Philadelphia, PA: Elsevier/Saunders; 2016.

22. Matsumoto $M$, Kunimitsu $S$, Wada $K$, et al. Vascular endothelial cell distribution and adhesion molecule expression in xanthoma. J Cutan Pathol. 2007;34(10):754-761.

23. Raskin R, Meyer DJ. Canine and feline cytology: a color atlas and interpretation guide. 3rd ed. St. Louis, MO: Elsevier; 2016. 
24. Avallone G, Helmbold P, Caniatti M, Stefanello D, Nayak RC, Roccabianca P. Spectrum of Canine Cutaneous Perivascular Wall Tumors: Morphologic, Phenotypic and Clinical Characterization. Vet Pathol. 2007;44(5):607-620.

25. Gross TL. Skin diseases of the dog and cat: clinical and histopathologic diagnosis. 2nd ed. Ames, IA: Blackwell; 2005.

26. Ide T, Uchida K, Kagawa Y, Suzuki K, Nakayama H. Pathological and Immunohistochemical Features of Subdural Histiocytic Sarcomas in 15 Dogs. J Vet Diagn Invest. 2011;23(1):127132.

27. Kato Y, Murakami M, Hoshino Y, et al. The Class A Macrophage Scavenger Receptor CD204 is a Useful Immunohistochemical Marker of Canine Histiocytic Sarcoma. J Comp Pathol. 2013;148(2-3):188-196.

28. Moore PF. A Review of Histiocytic Diseases of Dogs and Cats. Vet Pathol. 2014;51(1):167184.

\section{FIGURE LEGENDS}

Figure 1. Photomicrographs of a fine-needle aspirate from a cutaneous mass in a dog. Features consist of a marked perivascular cellular arrangement and cytoplasmic vacuolation, with indistinct cell borders. Wright-Giemsa stain. (A) x20 objective and (B) x50 objective.

Figure 2. Photomicrograph of histopathology of the excised cutaneous mass in a dog. Expansion of the dermis is characterized by a highly cellular, unencapsulated, infiltrative proliferation of sheets of spindled to round cells with vacuolated eosinophilic cytoplasm and indistinct cell borders. Mitoses were two per ten high power fields (400x magnification). H\&E stain, (A) x4 objective, and (B, C) x10 objective.

Figure 3. Photomicrograph of immunohistochemical antibody binding in the excised cutaneous mass from a dog. Cytoplasmic binding with both (A) CD18 and (B) Iba1 antibodies. H\&E stain, x10 objective. 

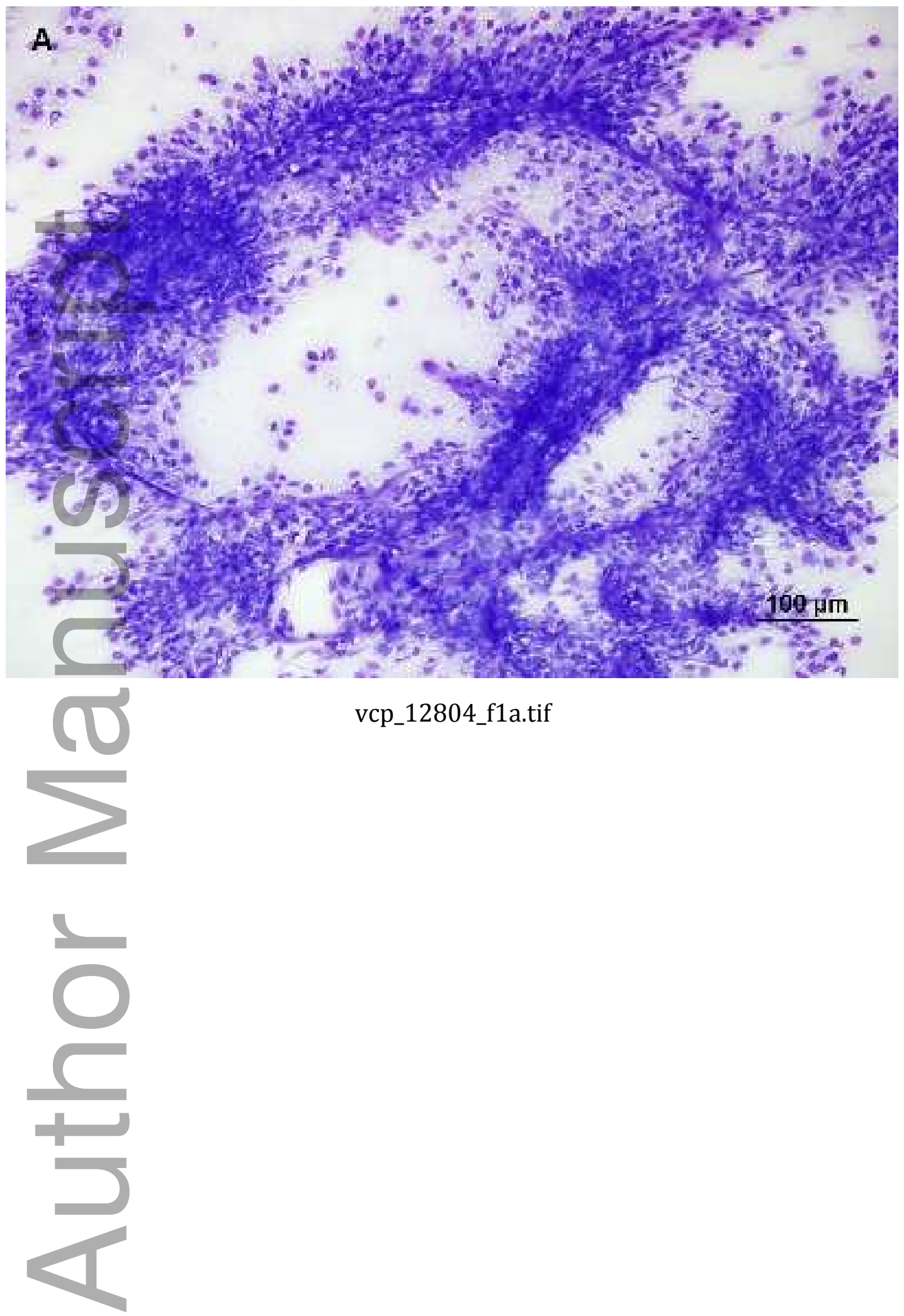


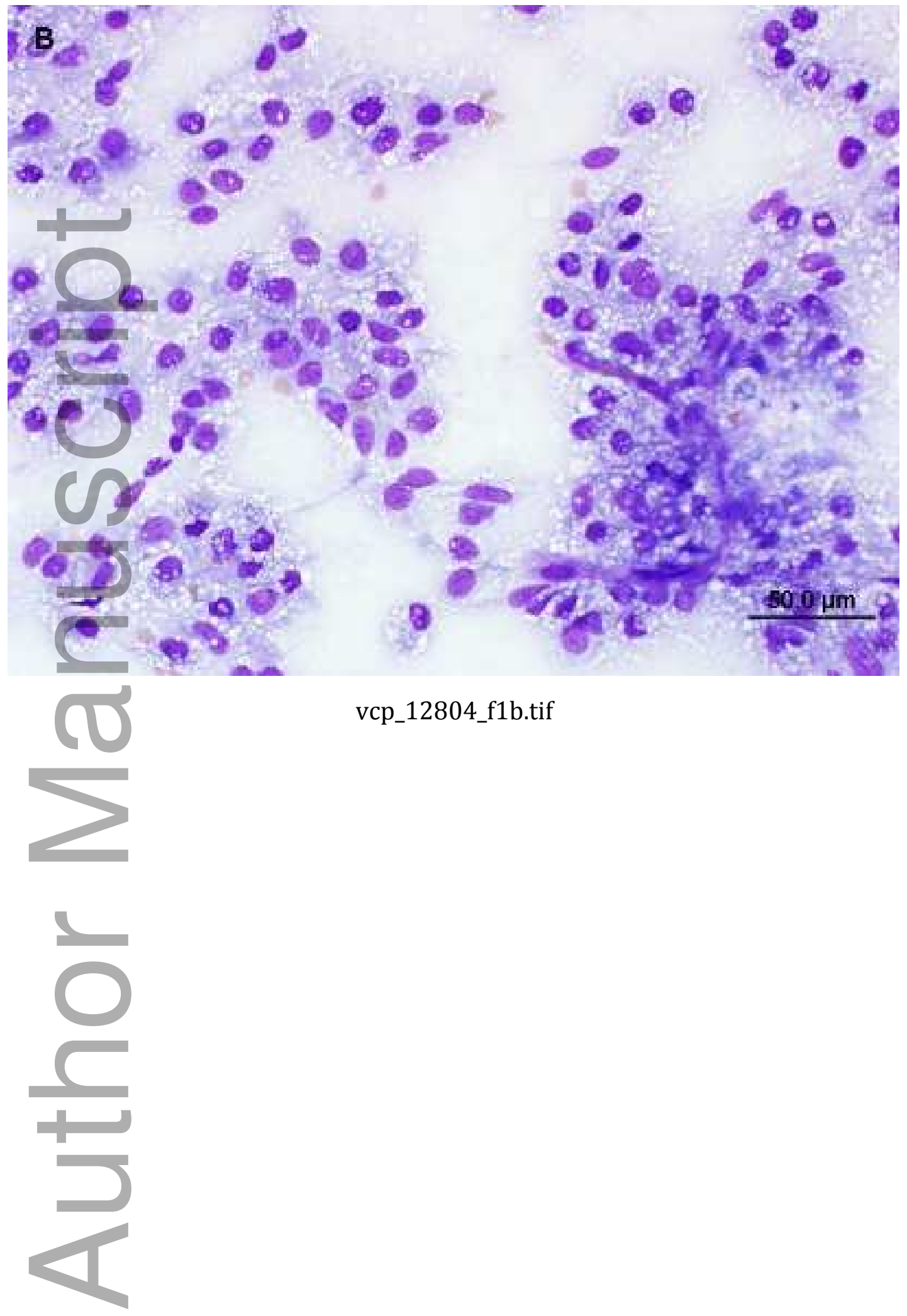

This article is protected by copyright. All rights reserved 

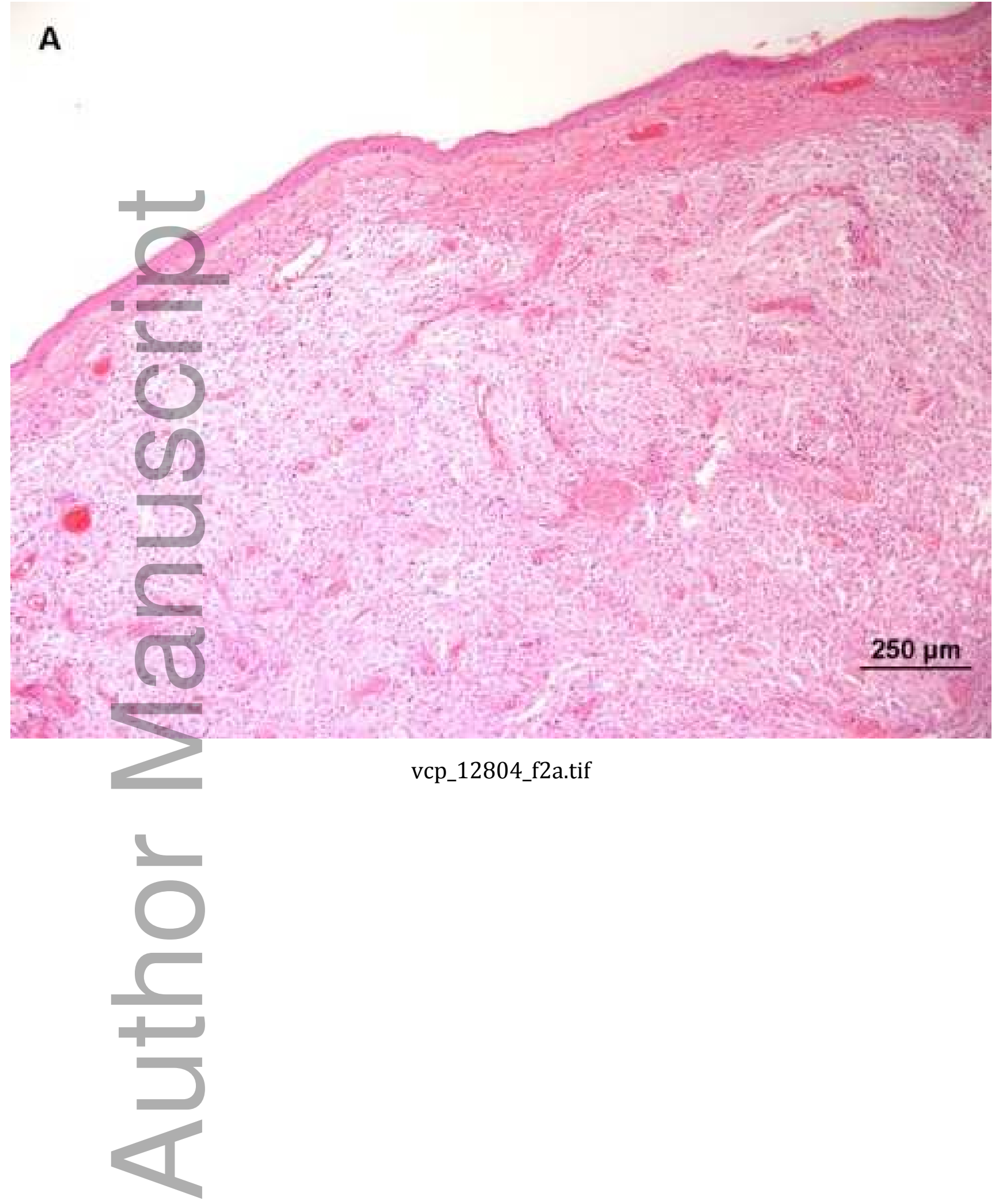

This article is protected by copyright. All rights reserved 

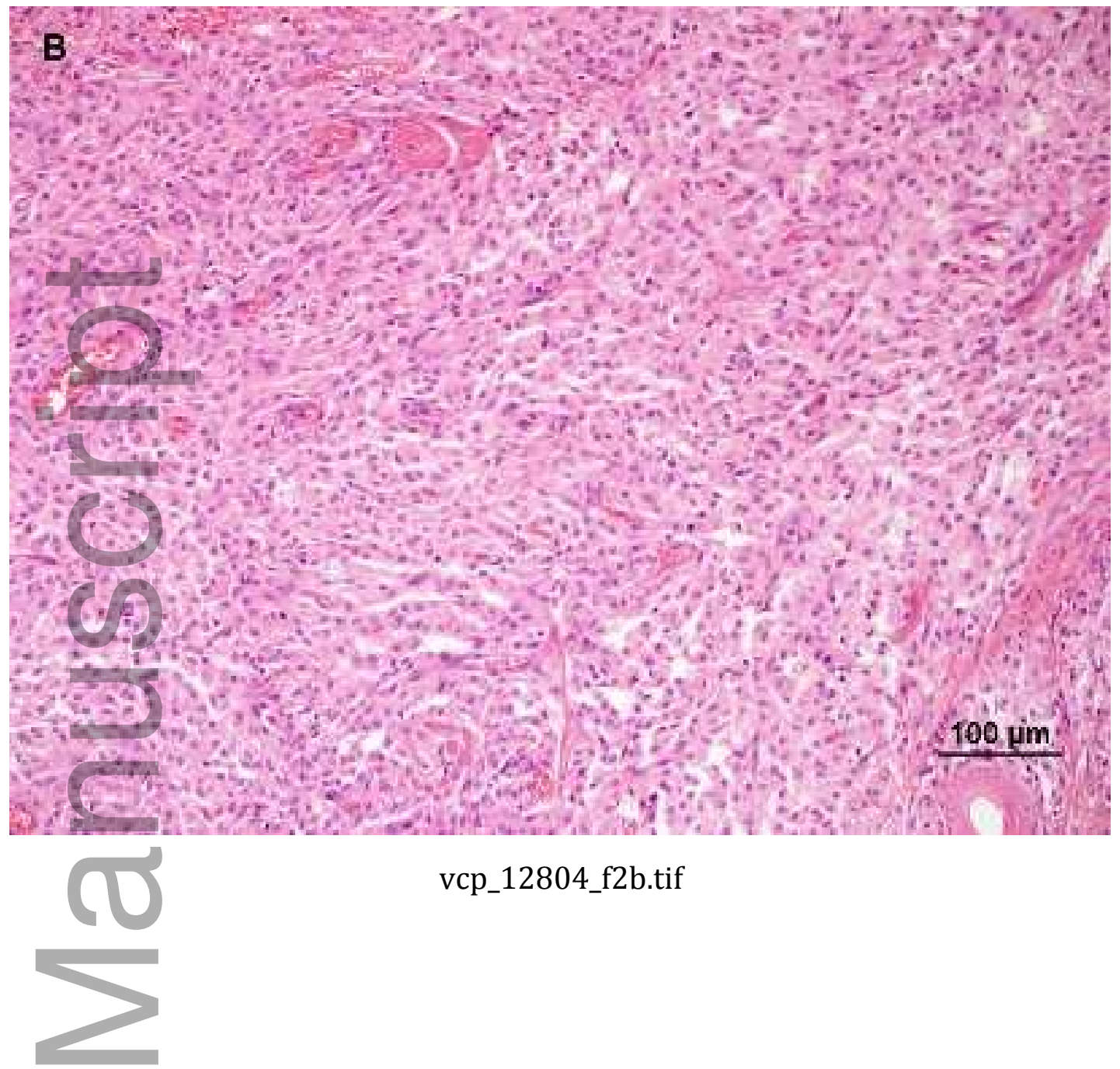

vcp_12804_f2b.tif



This article is protected by copyright. All rights reserved 

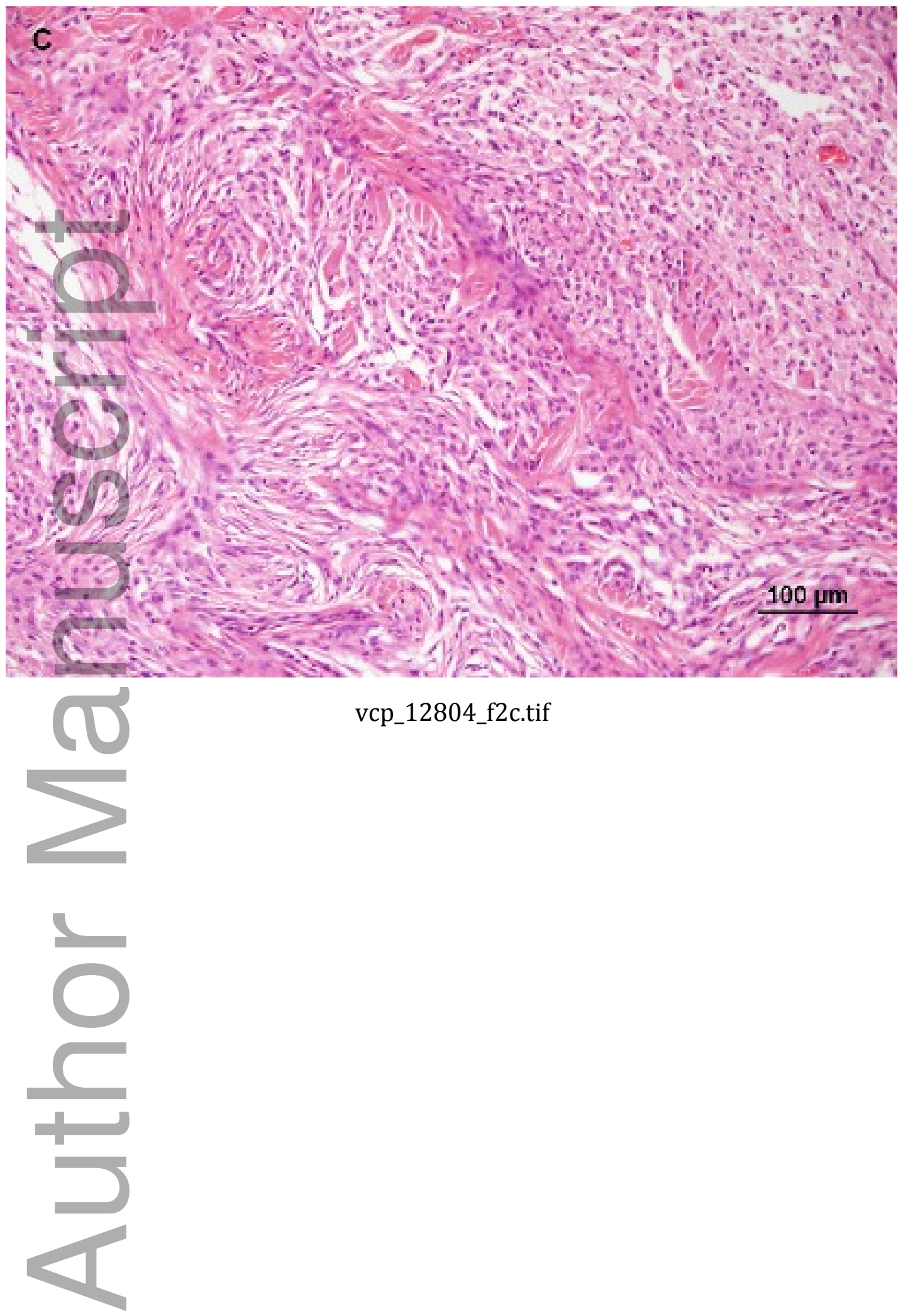

This article is protected by copyright. All rights reserved 

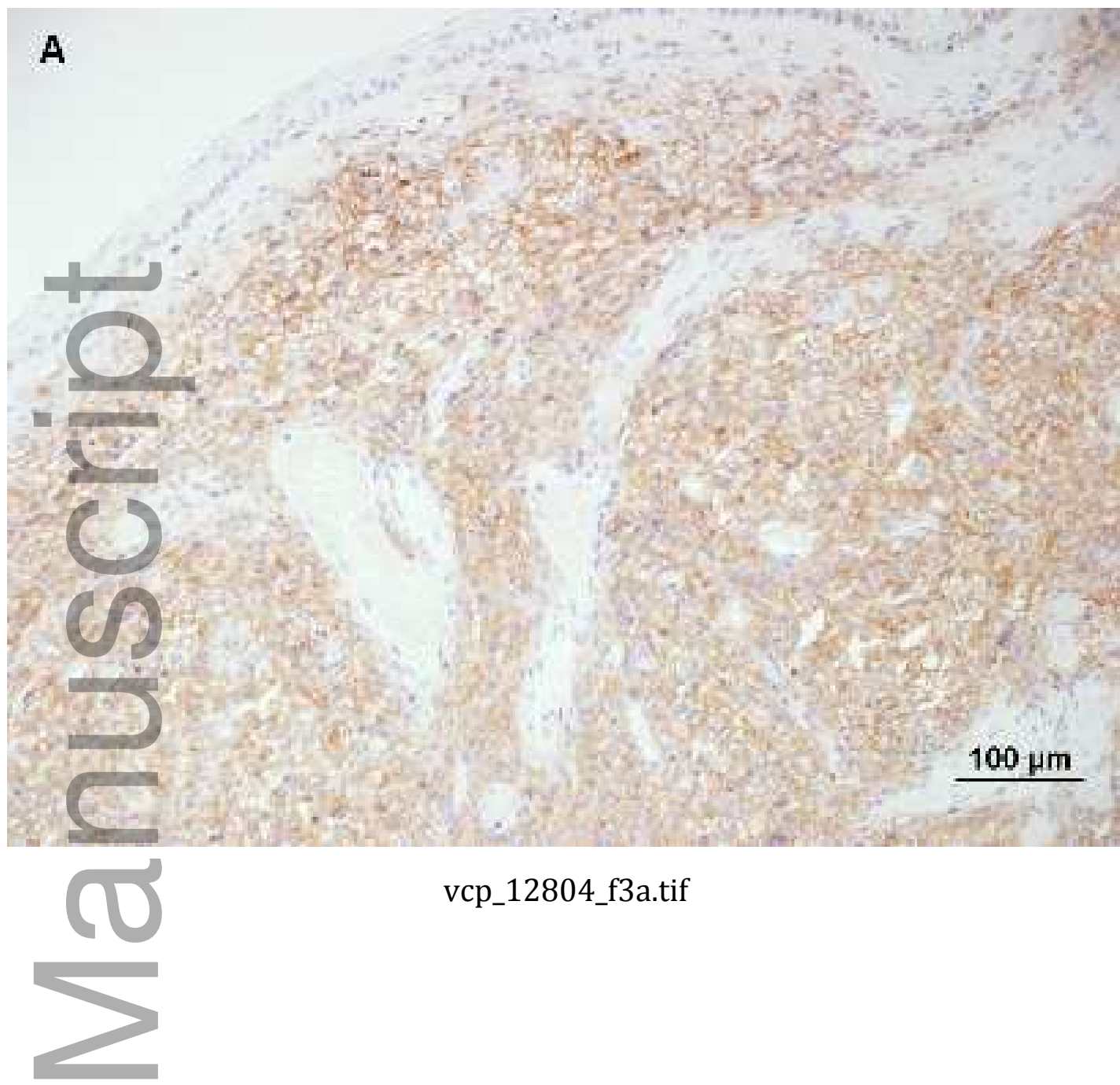

vcp_12804_f3a.tif

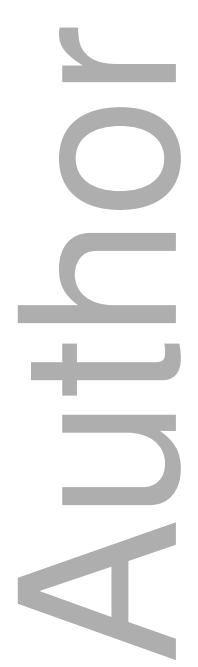

This article is protected by copyright. All rights reserved 

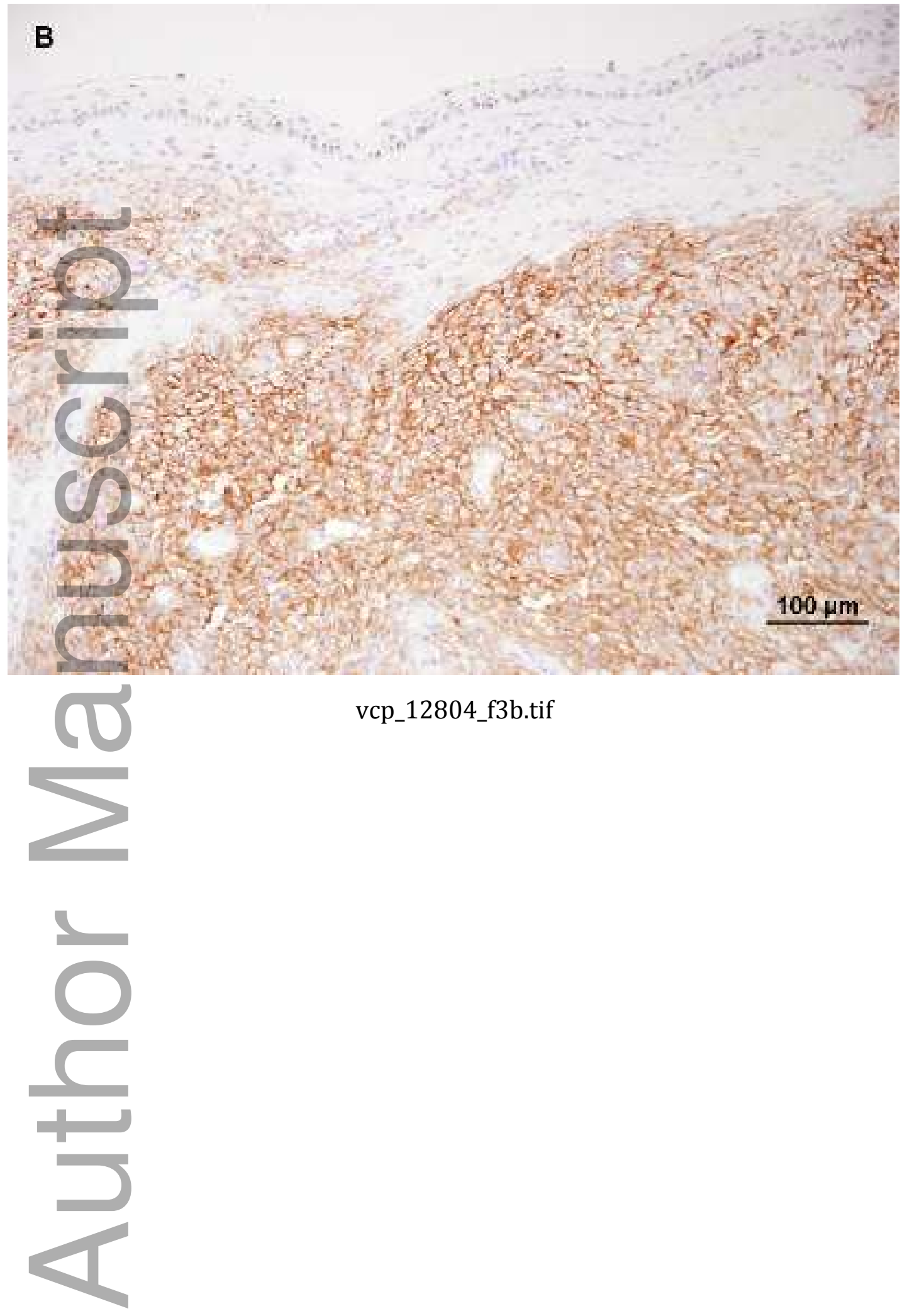

vcp_12804_f3b.tif

This article is protected by copyright. All rights reserved 


\section{University Library}

\section{- M M N E R VA A gateway to Melbourne's research publications}

Minerva Access is the Institutional Repository of The University of Melbourne

Author/s:

Russell, EB;Courtman, NF

Title:

Unique cytologic and histologic features of a suspected cutaneous xanthoma in a dog

Date:

2019-11-25

Citation:

Russell, E. B. \& Courtman, N. F. (2019). Unique cytologic and histologic features of a suspected cutaneous xanthoma in a dog. VETERINARY CLINICAL PATHOLOGY, 48 (4), pp.716-720. https://doi.org/10.1111/vcp. 12804.

Persistent Link:

http://hdl.handle.net/11343/286658 